\title{
BMJ Open A balancing act: a phenomenological exploration of medical students' experiences of using mobile devices in the clinical setting
}

\author{
F Rashid-Doubell, ${ }^{1,2}$ S Mohamed, ${ }^{1,3} \mathrm{~K}$ Elmusharaf, ${ }^{1,4} \mathrm{C}$ S O'Neill ${ }^{1,3}$
}

To cite: Rashid-Doubell F, Mohamed S, Elmusharaf K, et al. A balancing act: a phenomenological exploration of medical students' experiences of using mobile devices in the clinical setting. BMJ Open 2016;6:e011896. doi:10.1136/bmjopen-2016011896

- Prepublication history for this paper is available online. To view these files please visit the journal online (http://dx.doi.org/10.1136/ bmjopen-2016-011896).

Received 14 March 2016 Revised 6 April 2016 Accepted 8 April 2016

CrossMark

\author{
${ }^{1}$ Royal College of Surgeons \\ in Ireland-Bahrain, Busaiteen, \\ Kingdom of Bahrain \\ ${ }^{2}$ School of Medicine, \\ RCSI-Bahrain \\ ${ }^{3}$ School of Postgraduate \\ Studies and Research, \\ RCSI-Bahrain \\ ${ }^{4}$ Graduate Entry Medical \\ School, University of \\ Limerick, Limerick, Ireland
}

Correspondence to Dr Fiza Rashid-Doubell; frdoubell@rcsi-mub.com

\section{ABSTRACT}

Objective: The aims of this study were to describe the experiences of senior students using mobile devices in a clinical setting while learning and interacting with clinical teachers, patients and each other, and to identify challenges that facilitated or impeded the use of such devices in the hospital. Design: Interpretative phenomenology was chosen to guide our enquiry. Semi-structured interviews were conducted to examine the experiences of five senior medical students using mobile devices in the clinical setting.

Setting and participants: Senior medical students at an international medical school in the Middle East. Results: Three main themes emerged from the data analysis: learning; professional identity and transitioning from student to doctor. The findings showed that using mobile devices in the clinical area as a learning tool was not a formalised process. Rather, it was opportunistic learning at the bedside and on occasion a source of distraction from clinical teaching. Students needed to negotiate relationships between themselves, the clinical teacher and patients in order to ensure that they maintained an acceptable professional image. Participants experienced and negotiated the change from student to doctor making them mindful of using their devices at the bedside. Conclusions: Mobile devices are part of daily life for a medical student and there is a need to adapt medical education in the clinical setting, to allow the students to use their devices in a sensitive manner.

\section{INTRODUCTION}

Technological advances over the past decade have led to the development of portable, lightweight and inexpensive mobile devices. A number of definitions have been suggested to describe the current generation of mobile devices. ${ }^{1}{ }^{2}$ In short, a mobile computing device is portrayed as one in which multiple functions such as multimedia access, communication, picture and audio capture are integrated into one device. ${ }^{2}$ These
Strengths and limitations of this study

- The findings add to the body of literature that medical students engage in a complex negotiating process in the clinical environment while using mobile devices as a learning tool.

- Most of our findings were new and some concurred with previous studies.

- The sample was purposive and homogeneously selected to balance for gender and nationality.

- Our research was limited to a single cohort of senior cycle students.

multifunctional, multipurpose instruments have transformed our social and working lives. A range of studies have also identified the uses, attitudes and barriers in using mobile technology during preclinical and clinical training. ${ }^{2-5}$ The benefits of mobile learning include portability, flexibility, information management, communication and time management. ${ }^{1}$ Their place in learning is evident; studies have even described their potential to enhance student learning. ${ }^{2}$ However, there are pitfalls in using the devices in a medical educational setting, particularly in the clinical setting. They include superficial learning, distraction, dependency and a lack of regulation. ${ }^{1-3}$ Despite these pitfalls, there is consensus that this technology facilitates wider access to information and knowledge. ${ }^{6}$ Thus, the potential of mobile devices as learning and teaching tools is considerable and exponential, facilitating a transition from a didactic, teacher-centred approach to a more constructivist studentcentred one. ${ }^{7}$

Mobile learning is generally perceived as offering students the opportunity to learn without the limitations of time and place, thereby allowing the learner to construct a more creative method of learning while moving away from the more traditional 
approaches. This change also has the advantage of being learner-centred. In medical education, the use of mobile devices has been shown to encourage student learning in, as well as beyond and across the individual situations. ${ }^{8}$ Others have shown that although the access to information is rapid, there is a tendency to overuse or even become over-dependent in using mobile devices; this may be inhibiting the internalisation of knowledge, thus leading to the potential for superficial learning. ${ }^{2}$ Furthermore, in that study, the participants anticipated that mobile devices would replace the use of traditional textbooks, and that their use would soon be a part of routine clinical care. ${ }^{2}$ Recent studies have cautioned against reading off internet-enabled mobile devices and have suggested that learning in a multitasking manner may result in distraction. ${ }^{9} 10$

There is plenty of literature quantifying the use of mobile phones by science, pharmacy and even medical students. ${ }^{11-13}$ In the latter discipline, investigators have recently highlighted the use of mobile devices for teaching and learning in clinical medicine, described the evolution of mobile device use in the clinical setting and set out the uses and benefits of mobile devices for healthcare professionals. ${ }^{14-16}$ However, there appears to be a gap in qualitative studies capturing the students' experience of using mobile devices in the clinical setting. The aim of our study was to fill this gap and describe the experiences of senior students in their fourth year of a 5-year medical programme of using mobile devices in a clinical setting while learning and interacting with the clinicians, patients and each other. In addition, we sought to identify challenges that impeded the use of devices in the clinical setting and any factors that facilitated or inhibited the use of the devices.

\section{METHODOLOGY AND METHODS}

\section{Research methodology}

A phenomenological design was considered the most appropriate to best generate the data needed to meet the aims of the study. Phenomenological research is the study of the lived experience and the life world with the aim of achieving a deeper understanding of the nature or meaning of one's everyday experiences The concepts underpinning phenomenology originated from the philosophies of Husserl and Heidegger and were further developed and elaborated on by Merleau-Ponty. ${ }^{17}$ The philosophical emphasis on individual experiences led to the development of phenomenology as a research method, an approach that has been deemed especially suitable for researchers attempting to uncover and describe the essence of everyday experiences. ${ }^{18}{ }^{19}$ While there is much debate surrounding the differing methodological approaches to phenomenology, the choice of which methodology to use usually fits with a researcher's philosophical leanings and the pragmatic concerns of a study. ${ }^{20}$ Similarly, methodological decisions are also aligned to analysis frameworks. For example, Colaizzi provides a framework for analysis drawing on the philosophical ideals of Husserl, ${ }^{21}$ while Max van Manen, who has a particular interest in pedagogy, aligns his procedures with the ideas of Merleau-Ponty. ${ }^{17}$

Since the authors in this study had knowledge and experience of applying Smith's procedures and analysis framework, a decision was made to follow his approach which he calls interpretative phenomenological analysis (IPA) ${ }^{22}$ Smith developed this framework within the discipline of psychology and it has become increasingly popular within the disciplines of healthcare and educational research. ${ }^{23-26}$ The procedure of IPA situates participants in a specific context and facilitates the exploration of personal reflections and experiences with an emphasis on individual idiographic experiences (ref. 22, p. 29). This is achieved by generating data through in-depth face-to-face interviews. ${ }^{22}$

\section{Methods \\ Participant selection}

Once the investigation received ethical approval from our institutional Research Ethics Committee, participants were then selected (6 interviews, 3 men and 3 women and a mixture of 3 local and 3 international senior medical students) on the basis of their gender and nationality with the aim of ensuring that the sample was as representative of the senior cycle class as possible. These individuals were contacted to take part in the study through email.

\section{Sample size}

The sample size was also shaped by two additional factors, the depth of data conveyed by the interviewees and the emergence of common themes during data analysis. The IPA method does not impose criteria in relation to sample size with even a single interview being deemed sufficient, if it provides a detailed account of the experience being investigated. ${ }^{22}$ In addition, if the topic guide is carefully constructed, then a great deal of data can be captured with several interviews, with a default number of three being given by Smith $e t a l^{22}$ which allows for sufficient microanalysis of the data.

\section{Interview guide}

The interview topic guide questions were developed by three of the authors (CO'N, KE and FR-D) to ensure that participants were given the opportunity to provide full, rich accounts of their learning experiences with mobile devices. In addition, the topic guide was focused around six key questions but was flexible enough to permit the interviewer to follow-up and probe interesting areas as they emerged. The participants were asked to meet the interviewer at a time which was most convenient to them. A reminder was sent to them the day before by email with the corresponder providing them with details including the time, venue and person who was to meet and interview them. 


\section{Interviews}

Individual in-depth semi-structured interviews were conducted face-to-face by two of the four authors, (FR-D and SM) in a private office space located in the medical school. The interview consisted of two people, the interviewer and the interviewee, and began with a verbal explanation of the voluntary nature of the interview and the freedom to withdraw at any point and an explanation of how confidentiality was going to be maintained before the consent form was signed. The interview was initiated with an icebreaker and went on to discuss the participant's current use of mobile devices, more specifically their experiences of using mobile devices in the clinical setting; the duration of each interview was variable, ranging from $30 \mathrm{~min}$ to $1 \frac{1}{2} 2$ hours.

There were no follow-up interviews and one student after conducting the interview requested that their interview be removed from the data. This request was honoured.

\section{Audio recordings}

Interviews were audio recorded and the student was not identified on the tape. The digital data was password protected and was sent to a professional transcribing company to be transcribed verbatim. There was no relationship established prior to the study between the interviewer and the participants, and the reason for conducting the study was revealed at the beginning of the conversation before the icebreaker. Transcribed interviews were not returned to the participants for feedback.

\section{Data analysis}

Smith et $a t^{22}$ describes data analysis in IPA as an iterative and inductive process and suggests eight differing strategies in order to develop the analysis from a particular case to the collective cohort and to move from the descriptive to the interpretative. The suggested eight strategies are not 'cookbook' rules, rather more akin to principles to be used during the analysis. In addition, Smith presents a specific six step guide to assist novice researchers who may require more specific instructions to develop their analysis (ref. 22, pp. 82-103).

In this study following the transcription of the three interviews, the authors read and reread the transcripts several times, making their own personal notes and reflections. Then the transcribed notes along with field notes were subjected to line-by-line analysis by three of the four authors (CO'N, FR-D and KE), paying close attention to experiential claims, concerns and understandings of the participants. Key words, phrases and/or descriptions from the participants were documented, as the authors reflexively engaged with the data. Convergence and divergence of data were noted, leading to the development of preliminary emergent themes. These themes were further interrogated and refined with reference to participants' original words while also including the author's collective interpretations. Following this preliminary analysis, a further three interviews were conducted. These data from two of these interviews were similarly analysed, resulting in some minor reconfiguration and relabelling of themes. Based on no new data collected from the new interviews, no further interviews were deemed necessary.

\section{RESULTS}

Three main themes each comprising of three subthemes emerged from the data analysis.

I. Learning: building knowledge and understanding, information gathering, distraction

II. Professional identity: professional identity with the patient, professional identity with the clinical teacher, professional self-identity

III. Transitioning from medical student to doctor: the change process, clinical skills acquisition, negotiating relationships

\section{Learning}

The following section will present the findings on this theme. This theme consisted of the following subthemes: building knowledge and understanding, information gathering and distraction.

Learning by the participants while using their devices was intermittent and context dependent. The clinical setting and their learning needs shaped and determined how and when the student used the mobile device. It was clear that different kinds of learning were underpinned by information gathering. The data showed that the students used their devices to gather information rapidly. This information gathering facilitated learning about a clinical topic at the bedside and this understanding was later augmented when the student left the clinical area at the end of the day. While learning emerged as the core feature for students in the clinical setting, it seemed that the process of acquiring information also presented opportunities for distraction. This distraction in turn created obstacles that impeded the learning process.

\section{Building knowledge and understanding}

The students used their devices to access information rapidly while in the clinical setting. This instant access to information had a dual purpose: first, allowing individuals to appear knowledgeable during clinical sessions, which made them appear informed on the discussion topic on which they were being quizzed, and second, allowing them to build their understanding of a topic while in the clinical setting, thus 'filling in the gaps' between what they had learnt in the classroom and what they should know in the hospital setting. There appeared to be no limitations in how the device was being used in the hospital since participants appeared to have the ability to use the device for learning while 
also simultaneously using it for social media connectivity, as evidenced by the data below.

P.3-I always pull out my phone whenever I can so as soon as, like I said, anyone has turned around I'm looking things up because I'd rather you know get as much as information as I can to make myself sound like I know what I'm talking about. Be prepared...I use my device for communication, entertainment and education...I use it for a bunch of things.

P.4-I have instantaneous access, I have don't have to worry about anything...I have an app that I've downloaded Wikipedia on it. So even when I have no data connection I have instantaneous access to almost anything the doctor is mentioning. Instantaneous, I don't have to worry about anything.

P.5-I use it either for communication you know the social networking and educational other than using it as a phone.

This rapid accessing of information provided sufficient knowledge but was dependent on opportunities to gather information in the clinical setting.

\section{Information gathering}

Information gathering played an important role in learning while in the clinical setting and depended on the participants' opportunities to gather information, and these were limited in the hospital environment. This was in part due to a perceived stigma of participants using the devices in the clinical area as they may appear unprofessional. However, the lack of bedside opportunities to access information did not impede them from learning, as students found time outside of bedside teaching to augment their knowledge.

P.1-I don't use my phone immediately. I will write down the things we didn't know, we nod our heads and then when we leave we'll sit on our tea break and look them up quickly to make sure we understand or we know what we are talking about.

P.4-I'd like to think that I would use my phone, my iPad etcetera, in order to sort of try and get as much information as possible.

Although the information gathering process was intermittent, it also presented the participants with an opportunity for being distracted.

\section{Distraction}

Several students explained how they found using mobile devices a distraction, particularly during patient observations. Learning at the bedside is a unique feature of being in the medical/clinical environment and the participants understood how vital it was to their learning to focus on the patient and doctor interaction during clinical examinations.
Individuals described how using technology distracted them from the bedside learning (P.1). This included the fact that using the device impeded the development of a relationship between their most essential learning resource, the experienced clinical teacher. Participants described how some teachers did not like students using devices as it detracted from their clinical learning.

P.3 - They don't really want us to have laptops or anything because I think they don't really trust us to be focusing on them if we're typing away or something.

P.1-If you're using the phone you might be looking something up but then you get distracted to go into Facebook or something else because it's there, you get a message at the same time, so it's distracting. So you might not learn too because you're missing information by being distracted.

P.4-Because I want to get as much information as I can from the clinician, who obviously has years upon years, upon years more of knowledge and experience than me...Like oh that student is supposed to be focusing on me. Instead he's looking at his mini iPad.

P.5-Like some of them they are like obviously they are not studying because they keep writing/texting, like you see their fingers moving, they are talking to someone. They are not focusing or anything.

Learning was therefore fragmented and opportunistic, allowing participants to either establish sufficient baseline information to build on later or to fill in the gaps in their knowledge between classroom teaching and bedside learning. It seemed that this was a balancing act between using the mobile device for checking information and building knowledge during clinical sessions and being distracted by the social connectivity opportunity. A core concern was the awareness of all participants of the importance of developing and maintaining a professional identity in the clinical setting.

\section{Professional identity}

The second theme that emerged from the data centred on professional identity. This theme comprised of three subthemes: professional identity in front of the patient, professional identity in front of the clinician and their own professional self-identity.

\section{Professional identity in front of patients}

The data from the participants evidenced that using the devices in front of the patients presented the individuals with discretionary dilemmas. Many of the students described how they struggled to control the temptation of using their devices in front of patients. However, they characterised this as 'rude', with some interviewees feeling that 'patients [may] even be disgusted', while on the other hand others detailed the ambivalence of patients and in particular their passivity and habituation in seeing technology used around them. 
P.1-To be honest I don't use it when I'm in front of a patient or with the doctors. If we walk outside and we now are discussing something then no problem I can look it up but I try not to...So I think all of this type of stuff now it's becoming...patients are becoming used to it, they're becoming used to seeing it, and they now know that's what the purpose of it is.

P.3-Oh I wouldn't use it in front of a patient, I think that would be pretty rude, because I mean that's just rude

P.4- "I haven't seen anyone literally use their phone while talking to a patient. Now that would be very rude"...Patients are usually very passive, they're more afraid of what the doctor might say, as in you know you have this, than you know what we're doing.

P.5-I thought the patient was looking at me, I don't know, that's how it happened. At first it was like disgust with what he was seeing like, this is supposed to be a doctor? He [the student] is looking at his phone, although I was looking for information...Because patients were accepting that students had to learn so you look in a book in order to learn but now with the mobile device I'm just thinking how acceptable is that for patients when they're thinking 'Is he looking at a mobile device for learning?

One participant in particular voiced a concern that using their device in front of the patient interfered with good communication and good patient care. All the interviewees in this study requested patient permission before using their technology with most going on to describe the action they were undertaking to the patient before using their device. In fact, one person mentioned how the size of the mobile device determined the permissibility of use in front of the patient with tablet devices being acceptable and smaller smart phones not.

P.2-I try to minimise use of iPad while talking with the patient or interviewing them, or seeing them. Because it shows more respect when looking at them and taking more care of them.

P.1-Look, I'm going to look something up now' and you put your tablet down and you're looking something up. They know you're looking something up because it's a tablet...I think they can distinguish as well you know if it's something this size which is the $\mathrm{S} 4$, as with the Galaxy, or if it's a notebook, they can see the difference because they know obviously a notebook. No one is going to be using as a phone so you know they can see... I think just by size you can just...visually you can see what is a phone and what could be distracting.

The data evidenced that projecting a professional identity in front of the patient was of utmost importance to students and it was significant for them not to appear 'insincere or disingenuous' in front of the patient and to maintain eye contact during the consultation.
Participants' concern over maintaining professional identity extended to their interactions with their clinical teachers.

\section{Professional identity in front of clinical teachers}

The data evidenced that clinical teachers did not overtly encourage the use of mobile devices during bedside teaching. The participants categorised the teachers as being either 'old school', a term they frequently assigned to the older generation, or 'new school', a term afforded to more youthful practitioners-the former being described as 'paper-dependent' and being offended when interviewees used their devices in front of them. Many of the 'old school' doctors did not appear to understand the reliance that the younger student generation have on their mobile devices as learning tools. This dissonance appeared to create a feeling of reluctance among participants to bring mobile devices into hospitals when being taught by older doctors.

P.5-Many of the old, especially the old generation, they don't know how to use the technology properly, okay. And they don't know like how we use it and how do you put books and notes and whatever on the phone... they don't know how we live on our phone nowadays.

P.1-You know someone will say 'Hey put your phone down' or 'Check your message later' or something and you can't say 'Oh I'm actually looking...' it just looks unprofessional so to be honest I don't use it when I'm in front of a patient or with the doctors... When we...on an actual round I am very careful not to pull my phone out because it's still a phone you know so I think the stigma is that you're then distracted because it's a phone and it could be...you know if the doctor is talking.

P.2-Because they think that I'm not concentrating with them while using technology, whether it's iPhone or iPad. Although I'm writing notes or something, but they didn't like the fact that, in the beginning they didn't like the fact that I'm using this.

P.3-I've seen people do it you know where they're actually like genuinely looking at stuff or writing notes down because they've got the same phone and then the doctor would be like, that's really rude, put your phone away.

P.4-I didn't want my phone out. I still had that old high school way of doing things, and we're like no phones allowed.

The 'new school' group of doctors accepted and even encouraged on occasion the use of technology in the clinical setting when participants provided an explanation before use. Some interviewees also voiced the stigma attached to individuals using the mobile device in front of the teacher as well as indicating an impression of unprofessional behaviour not to be shown in front of the doctor. 
P.2-I mentioned sometimes, there's incidents happen with the doctor and I have to explain to him. But I suppose it wasn't like a major issue, I didn't feel like bad or, I just explained to them what's the situation and everything went fine.

P.3-So if we're doing a round and nobody knows the answer to something they'll [the doctor] be like (snaps fingers) 'Look it up' and then it's just the race of who can type faster, you know.

P.5-I was looking for something on the phone he said on the lecture and he was like 'Stop using the phone! I was like 'I'm looking for stuff related to what you are talking about'. He was like 'Okay, no problem'...

P.1-I think the stigma is that you're then distracted because it's a phone and it could be...you know if the doctor is talking or patients are talking I try not to divert you know to be on my phone even though maybe it is something genuine, I'm looking up something. You know someone will say 'Hey put your phone down' or 'Check your message later' or something and you can't say 'Oh I'm actually looking...' it just looks unprofessional so to be honest I don't use it when I'm in front of a patient or with the doctors.

\section{Professional self-identity}

All of the participants seemed to experience a sort of love-hate relationship with their devices. They appeared to struggle between, on the one hand, using the device for knowledge acquisition and, on the other hand, with maintaining their professional relationship between themselves and the clinical teacher and between themselves and the patient. One participant described it as their 'lifeline', while another stated how 'technology has made medicine easy' and a third claimed that 'iPad is your best friend'. Other individuals, however, resisted using technology in the clinical setting 'I don't like iPads' and that people are 'actual prisoners to their phones'.

P.1-So it's almost like your lifeline is cut off and you actually can feel the absence in your life you know really you can feel it because you can't [use it]...there's no communication anymore between students...You know it's almost like you go backwards.

It seemed for some students that despite the proliferation of the use of mobile devices that communication between them as students was not optimal. Another described how you would be considered a freak if you did not use technology in the modern world.

P.3-You'd be a freak. I mean who doesn't use technology now?

P.4-An iPad is your best friend. You know, the way technology is progressing it's beautiful.
P.5-It's like the time of the internet and it's the time of the technology, like everyone has to live with it.

The participants were also aware that using the phone can block the building of relationships between them and patients as well as between them and the teachers. Some described how the use of the mobile device in the clinical area would be professionally inappropriate. For some participants, it seemed that using the device while also adhering to the principles of maintaining eye contact to ensure good communication with the patient was almost an impossibility.

P.1-I don't look like I'm distracted you know and I'm meeting you in the eye. I've got good eye contact and I'm making an attempt to make a relationship...I just think...I think your body will betray you, you know your facial expressions will betray you sometimes and I think...so yeah it's happened before where you're looking at something and you're smiling because you've looked at a message you know you shouldn't have.

P.4-If you're going to be looking at a pad, you just quick glance, but always maintain eye contact.

They also described how using the device interfered with building a relationship with the clinical teacher. They were aware that the teachers had years of experience and knowledge and they were keen to maximise their exposure to this wealth of information.

On the other hand, they also know that the device empowers them and they expressed how using a smartphone makes them look 'smart' and provides them with a continuous opportunity for self-evaluation. The device offers the participants a method to evaluate their clinical performance; for example, they can use the internet to establish the correct methods for patient examination.

P.4-I'd like to think that I would use my phone, my iPad etcetera, in order to sort of try and get as much information as possible.

The interviewees also expressed how the culture of the hospital affects the comfort level of students using technology in the clinical setting. The hospital culture in turn dictated the behaviour and acceptability of using the mobile devices while in the hospitals.

P.1-I notice that the hospital staff on the rounds uses a tablet. So I think all of this type of stuff now it's becoming...patients are becoming used to it, they're becoming used to seeing it, they now know that's what the purpose of it is.

P.4-That's quite technology friendly that hospital.

However, there appeared to be a struggle for the participants between the need to be clinically informed, drawing on scientific facts which are instantly available on the mobile devices, while simultaneously building 
and maintaining trusting professional relationships with the patient and the clinical teacher. The data strongly evidenced that learning to negotiate these professional relationships is pivotal in transitioning from medical student to doctor.

\section{Transitioning from medical student to doctor}

The last theme consisted of three subthemes, the change process, clinical skills acquisition and negotiating relationships. This was a dominant theme, as participants experienced and negotiated the transition from student to doctor. This transitioning begins as an apprenticeship where most of their learning is done in the hospital and they carry with them identifiers of being a student, mainly textbooks, notebooks and mobile devices. In addition, they acknowledged the need to use their clinical teachers as instructors for learning by closely observing and acquiring the skill of patient examination and as evaluators to assess them while demonstrating their own hands-on patient skills. They described how they used technology to facilitate this learning and to complement the skills being taught but not replacing them. They stressed the importance of observation while developing mastery and hands-on skills necessary for clinical examination. One participant described it as part of their learning as the 'full experience'. Part of this experience was learning to change (building the 'doctor image') and moving from being a student to a doctor. This process made the students more mindful of using their devices in the hospital. They were acutely aware how even the presence of a device could negatively impact on their image as a doctor.

\section{The change process}

Participants were aware that certain 'props' identified them as students. The participants described how traditional resources such as textbooks were known student identifiers. It seemed, however, that during this process of change students wrestled between moving from using traditional identifiers to more modern ones such as the mobile device.

P.1-If he's standing with a textbook under his arm and he's playing with his phone and you know you think 'Hmm, he's a student' you know and really it's in your face he's a student...You're carrying a library around, it's this big, big book and every time they need to reference something they are flicking through a hundred pages. It's going with them everywhere. I think it just looks untidy. I think you have to approach a patient as if you must tell them you're a student, you have to clarify this, and you've got to be transparent. But I think you shouldn't have to have a beacon on top of your head going 'I'm a student. I'm a student. I'm a student'. You must be a doctor. Act a doctor.

In addition, participants expressed how they were acutely attentive of their behaviour with the mobile device to avoid humiliation in front of patients, clinical teachers and peers. This avoidance of the 'embarrassment factor' featured heavily when deliberating over whether to show the student side and use the mobile device or display the persona of a doctor where they have confidence in their own abilities.

P.1-I mean if you carry yourself as a doctor you'll be trusted as such you know and then that means maybe you'll get more information out of the patient, maybe they'll feel safer, they'll give you more...If we're not seen as students with tablets... When we ... on an actual round I am very careful not to pull my phone out because it's still a phone you know so I think the stigma is that you're then distracted because it's a phone.

P.3 - Nobody knows what you're doing [using the device] so they just basically write you off as rude.

In addition to being mindful of this metamorphic process they are undertaking, individuals were also aware of the importance of skills acquisition during bedside teaching. They were conscious that this was not something that could be learnt from a textbook or even from a mobile device; rather, it required an experienced teacher in situ to demonstrate appropriate clinical skills at the bedside with real patients while they keenly observed and made notes and practised.

\section{Clinical skill acquisition}

Interviewees described the importance of learning and practising clinical skills at the bedside. These two components appeared to be central to their progression towards becoming more confident and competent health professionals.

P.5-For example, if you are on the phone and your colleague did something, did a manoeuvre or did a technique, a specific technique, then if the doctor like felt that you are lost or not with them they'll tell you 'Can you do it for me?' and then you'll be like (laughs) you'll be embarrassed...This is the clinical knowledge where we use our phone but on the clinical skills you have to watch because nobody is going to teach you that unless you use it.

We are five as you said and one of us is examining the patient and the consultant or the resident or whatever was observing us. This is the time of observing not chatting or looking up information.

Body language also played an important part in the transition and projecting a more confident persona during patient assessment gave rise to better history taking and therefore a more accurate diagnosis.

P.4-The doctor's like you know it's a good opportunity, do an abdominal examination, so you know you've have to do it straight away, spontaneously and then you see retrospectively what you missed out. Then you can see why you do what you do... Their [clinical teacher's] body language, instead of being like this, or closed, it's just like 
calm. And that's what we try to convey. So when we get a better diagnosis, we get a better history, as opposed to okay, fine tell me.

Clinical skills were an essential part of bedside learning and needed to be seamlessly integrated into the role of learning to become a doctor. This learning was situated learning and involved both clinical teachers and the patients and required the participants to negotiate these relationships with care.

\section{Negotiating relationships}

The data strongly evidenced that students were negotiating relationships at many levels, first with the device itself, then with their teachers, as well as with their patients and finally with themselves as they developed their identity.

These negotiations required a certain amount of consideration from the participants, with some recognising the need to explicitly demonstrate that they are undertaking learning and knowledge gathering from their devices rather than socially connecting with their peers. Their use of, and therefore their relationship with, the device was dependent on the type of device being used in the clinical setting, some being more acceptable than others.

P.4-iPads are acceptable and phones are not...They don't like it when you usually use your phones, as opposed to iPads.

P.1-I think if you build the relationship and you know that at the touch of a finger you've got your tablet to now say 'Look, I'm going to look something up now' and you put your tablet down and you're looking something up. They know you're looking something up because it's a tablet.

The participants' relationship with the patient was central to bedside learning as they felt that use of devices during the consultation process hindered the development of a trusting relationship with the patient. One interviewee described how they felt in this situation and indicated that without books or mobile devices their performance was 'more trusted', with the 'patients feeling safer' as they spent more time building a relationship with the patient than 'fumbling with student props'.

In the clinical space, building a relationship with the clinical teacher was equally important and students were aware of the need to seek permission from the doctor before using their mobile devices. An example would be where the participant would seek permission to calculate medication dosage or when seeking supplemental information.

P.3-You know with their permission. When they tell you, look this up, or you know, calculate this index number or ratio.
Although the majority of students sought permission, a few did not, with some participants recalling some of their peers using their mobile device behind the doctor's back to avoid detection, 'then like I take it out quickly, search and close it and put it back' (P.4).

They justified this behaviour in terms of wanting to 'look smart in front of the doctor' (P.3). This need to fill the gaps in their knowledge was evident even during their free time when they used their devices to seek information to improve understanding.

In summary, the use of mobile devices on the surface appears to be straightforward with a simple decisionmaking process of whether it should be used, when, where and how. The findings from this study have strongly evidenced that this decision-making process is much more complex for medical students and necessitates negotiation in the clinical setting. There are many layers of complexity for students to negotiate as they move from being apprentices in the clinical area to fledgling doctors. The data have clearly evidenced that students use their mobile devices as frequently as the situation allows and they use it to gather information and to establish sufficient knowledge on a given clinical topic which is built on later. Overall, students appear to use their devices positively, but they can also be a source of distraction. The participants were mindful that overuse was inappropriate and that their use in the clinical setting could negatively impact on their professionalism in front of patients, clinical teachers and their peers. This was particularly evident in the theme of transitioning where participants described their mindfulness on building and maintaining their doctor identity and made apparent during intervals when students acquired clinical skills training at the bedside. Many described the overuse of the device as an impediment to building a trusting relationship with the patient.

\section{DISCUSSION}

The findings of this study have strongly evidenced that mobile devices are widely used as learning tools by students in the clinical setting. The experiences of participants using their devices in such a setting are both complex and dynamic. Learning is an essential part of developing into a medical doctor, but learning in the hospital environment adds another layer of complexity for individuals on when and how to use their devices in front of patients and their teachers. Some authors have separated the learning done with a mobile device into formal and informal. ${ }^{27} 28$ However, in our study, learning using the devices was neither recognised nor formalised, with many participants unsure of the legitimacy of the use of the device in the hospital. Research findings show that students situate their learning by taking the opportunities to gather information as the need arises, evolving into an anytime, anywhere culture. ${ }^{8} 29$ This situational opportunistic learning has been reported by others exploring the use of mobile devices in higher 
education. ${ }^{27}$ These authors commented on the necessity of social interactions and learning being critical components of situational learning. However, at the bedside, the social interaction is sometimes a three-way process between the student, the teacher and the patient, resulting in the learning being more patient-centred and the opportunity of using the device becoming more difficult. Rather, the learning done using the device appears to be more solitary, being used to gather information and not necessarily requiring any social interaction, other than between the device and the individual.

Knowledge building is also a necessary part of learning and during bedside learning, students used the devices for rapid acquisition of information (often described as 'just in time information, ${ }^{13}$ ) which provides sufficient knowledge for bedside interactions between the student and the teacher or the patient. Although this knowledge gain is transient, it seemed to accommodate the need for a quick fix of information necessary for their successful clinical teaching and learning sessions, allowing participants to appear transiently familiar with the clinical topics discussed. However, this augmented form of learning is more appropriate for the completion of a single immediate $\operatorname{task}^{30}$ rather than for lifelong learning. In order to strengthen their understanding of particular topics, individuals indicated that they built on this bedside acquired information later on in the day when they had finished in the clinical area.

Several studies have reported on the distraction caused by the use of digital devices in the educational settings, mostly classrooms. ${ }^{31-33}$ The devices, although incredibly useful as learning tools, also present opportunities for distraction from bedside learning and patient care. ${ }^{34} 35$ Some participants avoided the use of technology in front of patients as they considered it rude. This consideration of rudeness has also been reported by both patients and hospital staff. ${ }^{6}$ Some students experienced a sense of dissonance as to the legitimacy of using the device in the clinical environment. This sense of conflict seemed to arise because of the different attitudes of the clinical teachers towards students using mobile devices in front of them. This ambiguity in using the devices in front of clinical teachers has been described by Ellaway, where learners expressed frustration at the lack of trust from the teachers. This criticism has led to the negative feelings among users. ${ }^{1}$ There was, however, some relief for device users in our study as they experienced a more positive attitude when using technology in front of younger clinical teachers. They appeared more comfortable with use of such devices in the clinical area and they were described as 'new school' by participants, a term used to infer their acceptance of technology at the bedside, while the older, more experienced clinicians appeared to be less open to the use of devices as a learning tool. Some studies have shown that this may be in part due to the older clinical teacher requiring an upscaling or lack of their own technology skills. ${ }^{36}$ This impression of the older generation being dissatisfied with the use of educational technology by young adults has been mentioned recently in the context of teachers and parents and their need to make school learning clear and structured. ${ }^{28}$ Conversely, findings have shown that the discrete use of mobile devices in the clinical environment is educationally advantageous. ${ }^{1}$ However, regardless of their frequent use and their role in medical education, caution needs to be exercised in when and how they are being used. ${ }^{29}$

Although previous studies have touched on the development of personal identity, as exemplified by the mobile learning practices among teenage users, ${ }^{28}$ as well as a shift in professional identity illustrated by the move from doctors being vessels of medical knowledge to the device acting as a knowledge databank. ${ }^{2}$ These topics of identity transition and professional image while using mobile devices in the hospital setting seem to be little explored in the literature. We find in our study that this struggle of identity formation and maintaining professionalism at the bedside presents a real conflict in the device user. There is a concern that device distraction during bedside learning may bring about an increased rate of error and partial task completion. ${ }^{4} \quad 34 \quad 35$ Although this was not something experienced or mentioned by our participants, it is a genuine concern and a topic which needs further examination.

There is hope that a recent concept termed 'digital professionalism', grounded in medical professionalism and capturing the challenges and opportunities of professionals using digital media, may initiate a broader and more structured discussion on the use of mobile devices in medical education. ${ }^{37}$ Our findings have shown that the use of devices by students at the bedside is necessary, and so this recent article is required as it focuses on building a framework for the use of technology in medical education assembled around themes of proficiency, reputation and responsibility. For participants in our study, professionalism in front of the patient and the teacher was at the forefront of their minds. Their main concern was to look professional in their teachers' eyes and therefore they avoided the use of the device, which by extension engendered a more personal and trusting relationship with the patient. However, if the devices are necessary for the learning process (as we and other studies have indicated), then there arises a genuine dilemma for students of when to use them, and for teachers of when to permit their use during bedside teaching.

\section{Strengths and limitations}

Interpretative phenomenology is a strong methodology which has a dual focus on the unique characteristics of individuals and the pattern of meaning across participants. These qualities and the familiarity of the researchers in using qualitative methods for research resulted in the generation of rich experiential data from the five in-depth interviews. The study was designed by four experienced qualitative researchers with diverse backgrounds contributing to the data analysis and theme 
generation, ensuring a thorough and broad discussion. While the sample size may be considered small, it exceeds the figure of three suggested by Smith as an acceptable number for this type of study. In addition, our findings add to the body of literature that medical students engage in a complex negotiating process in the clinical environment while using the learning devices.

There were some limitations to our study, the main one being that our medical school is unusual in that it is an international institution in the Middle East with a large cohort of local students which makes up the largest percentage of total students, up to $40 \%$, with the remaining students coming from 30 different countries worldwide. Thus, attempting to generalise our findings to a different population of students in the Middle East or even other parts of the world may not withstand scrutiny. However, in our favour is the fact that some of our findings concur with those of other investigators who have investigated the topic in similar studies. ${ }^{12}$ Other limitations include the fact that the research was limited to a single cohort of senior cycle students and done as a one-off study, providing us with only an instantaneous picture with those particular students.

\section{CONCLUSION}

The use of mobile devices is part of daily life for a medical student, and we as educators need to adapt or rethink our teaching to allow them to be used in an appropriate and sensitive manner. Awareness is also needed by medical students that the use of the devices can negatively impact on their medical image in front of the clinical teacher and the patient.

Twitter Follow Khalifa Elmusharaf at @elmusharaf1

Acknowledgements The authors would like to acknowledge Mr Eric Clarke, Dr Martina Crehan and Professor Teresa Pawlikowska for their discussions and helpful assistance with this project.

Contributors FR-D, SM, KE and CO'N were involved in the design of the study. FR-D and SM conducted the interviews. FR-D, KE and CO'N carried out the thematic development. FR-D wrote the first draft of the paper. All authors made critical comments on all drafts of the paper, as well as read and approved the final manuscript.

Competing interests We have read and understood BMJ policy on declaration of interests and declare that we have no competing interests.

Ethics approval RCSI-Bahrain.

Provenance and peer review Not commissioned; externally peer reviewed.

Data sharing statement No additional data are available.

Open Access This is an Open Access article distributed in accordance with the Creative Commons Attribution Non Commercial (CC BY-NC 4.0) license, which permits others to distribute, remix, adapt, build upon this work noncommercially, and license their derivative works on different terms, provided the original work is properly cited and the use is non-commercial. See: http:// creativecommons.org/licenses/by-nc/4.0/

\section{REFERENCES}

1. Ellaway $R H$, Fink $P$, Graves $L$, et al. Left to their own devices: medical learners' use of mobile technologies. Med Teach 2014;36:130-8.
2. Wallace S, Clark M, White J. 'It's on my iPhone': attitudes to the use of mobile computing devices in medical education, a mixed-methods study. BMJ Open 2012;2:pii: e001099.

3. Grasso MA, Yen MJ, Mintz ML. Survey of handheld computing among medical students. Comput Methods Programs Biomed 2006;82:196-202.

4. Davies BS, Rafique J, Vincent TR, et al. Mobile Medical Education (MoMEd)-how mobile information resources contribute to learning for undergraduate clinical students-a mixed methods study. BMC Med Educ 2012;12:1.

5. Kho A, Henderson LE, Dressler DD, et al. Use of handheld computers in medical education. J Gen Intern Med 2006;21:531-7.

6. Bullock A. Does technology help doctors to access, use and share knowledge? Med Educ 2014;48:28-33.

7. Kala S, Isaramalai SA, Pohthong A. Electronic learning and constructivism: a model for nursing education. Nurse Educ Today 2010;30:61-6

8. Pimmer C, Mateescu M, Zahn C, et al. Smartphones as multimodal communication devices to facilitate clinical knowledge processes: randomized controlled trial. J Med Internet Res 2013;15:e263.

9. Baron NS. Do mobile technologies reshape speaking, writing, or Reading? Mobile Media Commun 2013;1:134-40.

10. Baron NS. "But Still It Moves": screens, print, and reading. Selected Pap Internet Res 2013;3-10.

11. Morris NP, Ramsay L, Chauhan V. Can a tablet device alter undergraduate science students' study behavior and use of technology? Adv Physiol Educ 2012;36:97-107.

12. Richard CA, Hastings JF, Bryant JE. Pharmacy students' preference for using mobile devices in a clinical setting for practice-related tasks. Am J Pharm Educ 2015;79:22.

13. Boruff JT, Storie D. Mobile devices in medicine: a survey of how medical students, residents, and faculty use smartphones and other mobile devices to find information. J Med Libr Assoc 2014;102:22-30.

14. Ventola CL. Mobile devices and apps for health care professionals: uses and benefits. Pharm Ther 2014;39:356.

15. Lumsden CJ, Byrne-Davis LMT, Mooney JS, et al. Using mobile devices for teaching and learning in clinical medicine. Arch Dis Child Educ Pract Ed 2015;100:244-51.

16. Brooks R, Creazzo J. Evolution of mobile device use in clinical settings. Proceedings of the Charleston Library Conference; 2014:3. http://dxdoiorg/105703/1288284315588

17. Van Manen M. Researching lived experience: human science for an action sensitive pedagogy. Left Coast Press, 2015.

18. Munhall PL. Nursing research. Jones \& Bartlett Learning, 2012.

19. Mackey S. Phenomenological nursing research: methodological insights derived from Heidegger's interpretive phenomenology. Int J Nurs Stud 2005:42:179-86.

20. Streubert HJ, Carpenter DR. Qualitative research in nursing: advancing the humanistic imperative. Lippincott Williams \& Wilkins, 2011.

21. Colaizzi PF. Psychological research as the phenomenologist views it. In: Valle R, King M, eds. Existential phenomenological alternative for psychology. New York: Oxford University Press, 1978:48-71.

22. Smith JA, Flowers P, Larkin M. Interpretative phenomenological analysis: theory, method and research. Sage, 2009.

23. Opie J, Southcott J. Schooling through the eyes of a student with vision impairment. Int J Sch Disaffect 2015;11:67-80.

24. Kolnes L-J. 'Feelings stronger than reason': conflicting experiences of exercise in women with anorexia nervosa. $J$ Eat Disord 2016:4:6

25. da Silva Cintra C, Bittencourt RA. Being a PBL teacher in computer engineering: an interpretative phenomenological analysis. Frontiers in Education Conference; 2015:abstract number 32614.

26. Latakiene J, Skruibis P. Attempted suicide: qualitative study of adolescent females' lived experiences. Int J Psychol 2015;17:79-96.

27. Gikas J, Grant MM. Mobile computing devices in higher education: student perspectives on learning with cellphones, smartphones \& social media. Internet High Educ 2013;19:18-26.

28. Chan NN, Walker C, Gleaves A. An exploration of students' lived experiences of using smartphones in diverse learning contexts using a hermeneutic phenomenological approach. Comput Educ 2015;82:96-106.

29. Hogue RJ. Tablet use within medicine. Proceedings from IADIS International Conference on Mobile Learning; 2013.

30. Entwistle N, Tait H, McCune V. Patterns of response to an approaches to studying inventory across contrasting groups and contexts. Eur J Psychol Educ 2000;15:33-48. 
31. Beland L-P, Murphy R. III communication: technology, distraction \& student performance. Centre for Economic Performance discussion paper. 2015. 1-43. http://eprints.Ise.ac.uk/62574/1/ dp1350.pdf.

32. Dahlstrom E, Walker J, Dziuban C. ECAR study of undergraduate students and information technology, research report. 2014. http:// www.educause.edu/ecar

33. McCoy BR. Digital distractions in the classroom phase II: student classroom use of digital devices for non-class related purposes. Faculty Publication, College of Journalism and Mass
Communication, 2016:1-15. http://digitalcommonsedu/ journalismfacpub/90

34. Richtel M. As doctors use more devices, potential for distraction grows. The New York Times 2011;14.

35. Smith T, Darling E, Searles B. 2010 Survey on cell phone use while performing cardiopulmonary bypass. Perfusion 2011;26:375-80.

36. Sclafani J, Tirrell TF, Franko OI. Mobile tablet use among academic physicians and trainees. J Med Syst 2013;37:9903.

37. Ellaway $\mathrm{RH}$, Coral $\mathrm{J}$, Topps $\mathrm{D}$, et al. Exploring digital professionalism. Med Teach 2015;37:844-9. 